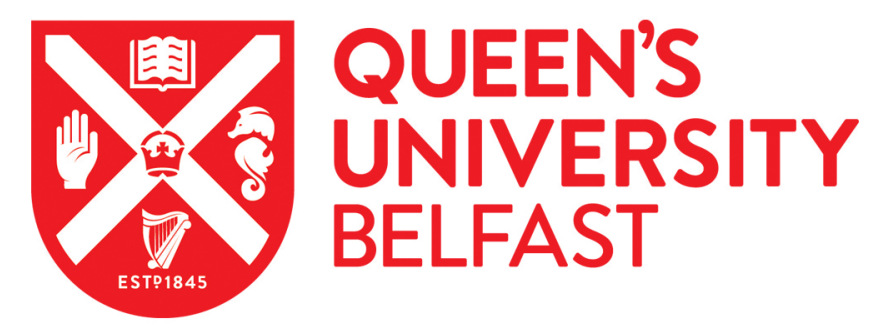

\title{
Direct Observation of Templated Two-Step Nucleation Mechanism during Olanzapine Hydrate Formation
}

Warzecha, M., Guo, R., M. Bhardwaj, R., Reutzel-Edens, S. M., Price, S. L., Lamprou, D. A., \& Florence, A. J. (2017). Direct Observation of Templated Two-Step Nucleation Mechanism during Olanzapine Hydrate Formation. Crystal Growth and Design, 17(12), 6382-6393. https://doi.org/10.1021/acs.cgd.7b01060

Published in:

Crystal Growth and Design

Document Version:

Peer reviewed version

Queen's University Belfast - Research Portal:

Link to publication record in Queen's University Belfast Research Portal

\section{Publisher rights}

Copyright 2017 American Chemical Society. This work is made available online in accordance with the publisher's policies. Please refer to any applicable terms of use of the publisher.

\section{General rights}

Copyright for the publications made accessible via the Queen's University Belfast Research Portal is retained by the author(s) and / or other copyright owners and it is a condition of accessing these publications that users recognise and abide by the legal requirements associated with these rights.

Take down policy

The Research Portal is Queen's institutional repository that provides access to Queen's research output. Every effort has been made to ensure that content in the Research Portal does not infringe any person's rights, or applicable UK laws. If you discover content in the Research Portal that you believe breaches copyright or violates any law, please contact openaccess@qub.ac.uk. 


\title{
Direct observation of templated two-step nucleation
}

\section{mechanism during olanzapine hydrate formation}

\author{
Monika Warzecha ${ }^{a}$, Rui Guo ${ }^{b}$, Rajni M. Bhardwaj ${ }^{c}$, Susan M. Reutzel-Edens ${ }^{c}$, Sarah L. Price ${ }^{b}$, \\ Dimitrios A. Lamprou ${ }^{d}$, Alastair J. Florence*,a,e
}

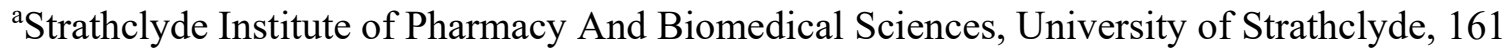
Cathedral Street, Glasgow, G4 0RE, U.K.

${ }^{b}$ Department of Chemistry, University College London, 20 Gordon Street, London WC1H 0AJ, UK.

${ }^{\mathrm{c} S m a l l ~ M o l e c u l e ~ D e s i g n ~ \& ~ D e v e l o p m e n t, ~ E l i ~ L i l l y ~ a n d ~ C o m p a n y, ~ I n d i a n a p o l i s, ~ I N ~ 46285, ~ U . S . A ~}$

${ }^{\mathrm{d}}$ Medway School of Pharmacy, University of Kent, Medway Campus, Anson Building, Chatham Maritime, Kent, ME4 4TB, UK.

${ }^{e}$ EPSRC Centre for Innovative Manufacturing in Continuous Manufacturing and Crystallisation, University of Strathclyde, Technology and Innovation Centre, 99 George Street, Glasgow, G1 1RD, U.K. E-mail: alastair.florence@strath.ac.uk

\section{KEYWORDS}

olanzapine, hydrates, two-step nucleation, templating, nanocrystals, ORIENT 


\section{ABSTRACT}

Investigating crystal nucleation at the nanoscale is of significant interest, in particular as more complex, non-classical routes have roused questions about the classical view of homo- and hetero-nucleation processes. Here, we report the direct observation of a two-step nucleation mechanism during the transformation of anhydrous olanzapine to olanzapine dihydrate. Atomic force microscopy studies of the dominant (100)OZPNI face of olanzapine form I single crystals in contact with water show the formation and growth of dense nanodroplets concentrated around ledge sites. In unstirred solution, apparent ordering and crystallisation from these droplets occurs with olanzapine dihydrate $\mathrm{D}$ produced by the templating effect of the underlying olanzapine I lattice. In contrast, under stirred conditions a kinetic dihydrate polymorph, dihydrate B, nucleates probably due to the detachment of nanodroplets from the surface during stirring and a consequent loss of template effect. Computational modelling of the binding of olanzapine growth units on crystal ledges reveals many strongly bound dimer positions unrelated to either crystal structure. This impedes surface integration and contributes to the growth of disordered clusters at the ledge site. Nanocrystal modelling shows that the (100) OzPNI surface favours the nucleation of dihydrate $\mathrm{D}$ over the kinetic form. This work gives an important insight into heterogeneous two step nucleation where the first step, the formation of a prenucleation droplet, can in the second step, bifurcate, either to produce the stable form by templating, or the kinetic form on detachment of the nanodroplets.

\section{INTRODUCTION}

Crystallisation is widely used to control the purity and solid-state properties of active pharmaceutical ingredients (API) and others chemicals. Despite its widespread application in 
industrial processes crystal nucleation and growth remain poorly understood. Hence, the study of early stages of crystal formation provides the opportunity to develop improved methods to control crystallisation outcomes including size, ${ }^{1}$ purity, ${ }^{2}$ morphology, ${ }^{3}$ crystal structure,${ }^{4}$ and the stability and performance of APIs. Nucleation and growth processes are difficult to monitor experimentally at the molecular level due to the short length and timescales typically involved, however considerable efforts continue to be devoted to understanding nucleation processes ${ }^{5}$ including using dynamic simulations. ${ }^{6}$ Classical Nucleation Theory $\left(\mathrm{CNT}^{7-11}\right)$ is widely applied to describe crystal nucleation kinetics from solution, however it cannot faithfully explain all observed phenomena. Recent studies have shown evidence of a two-step nucleation process ${ }^{12-15}$ in which the initial formation of clusters of a dense, disordered, liquid-like phase precedes the formation of an ordered solid nucleus inside the clusters. Evidence for two-step nucleation has been observed in protein crystallisation ${ }^{16-19}$ with the existence of pre-nucleation clusters (PNCs) comprising small, thermodynamically stable solute clusters also being reported for inorganic systems including calcium carbonate and calcium phosphate. ${ }^{20-23}$ It has been proposed ${ }^{20}$ that within PNCs local ordering of structural motifs corresponding to specific crystalline polymorphs can occur, influencing the resultant crystal form obtained. The formation of dense clusters has also been observed in aqueous solutions of organic molecules (including several amino acids such as glycine, aniline and DL-valine ${ }^{24-27}$ ), polymers ${ }^{28}$ and inorganic structures including heteropolyacids ${ }^{29}$ and InP quantum dots. ${ }^{30}$ The increasing evidence for two-step nucleation in organic, protein and inorganic systems suggests it may play a significant role in the formation of crystals under many different situations.

A two-step nucleation mechanism was proposed during the heterogeneous nucleation of organic molecules on carbon nanohorns. ${ }^{31}$ The impurity surface may have the ability to induce 
order within the dense pre-nucleation clusters and lower the surface free energy for nucleation as well as effectively template the resultant crystal form. There is therefore also considerable interest in the mechanisms controlling heterogeneous nucleation templating with surface topology, ${ }^{32,33}$ lattice matching, ${ }^{34-37}$ and molecular functionality ${ }^{38-40}$ factors influencing the process. Clearly, a better understanding of how surfaces can influence the structure of PNCs could provide a basis to select or design surfaces that specifically template crystalline materials with desirable solid-state properties. ${ }^{34,37}$ The key solid state properties of APIs include size, shape, crystal structure, surface properties, solubility, dissolution rate and stability. Hydrate formation is of particular importance due to the widespread exposure of APIs to water, whether in solution or vapour form, since the incorporation of water molecules in the crystal lattice can have a dramatic effect on solubility and possibly bioavailability of an API. The ongoing development of theories for nucleation and the role of surfaces on heteronucleation processes clearly needs further investigation, exploiting techniques that can operate at the nanoscale. One such technique is atomic force microscopy (AFM), commonly regarded as a surface-specific technique, with promising applications in various aspects of API characterization, such as crystal growth, ${ }^{41,42}$ surface morphology, ${ }^{43}$ phase changes ${ }^{44}$ and dissolution. ${ }^{45}$

Olanzapine $\left(\mathrm{OZPN} \text {, Zyprexa }{ }^{\circledR} \text {, Figure } 1 \mathrm{a}\right)^{46}$ is a BCS class II drug used in schizophrenia treatment. To date, 60 distinct OZPN forms have been identified, including three polymorphic forms (I, II, III), where form I is the most stable non-solvated form. ${ }^{47}$ The drug also forms three polymorphic dihydrates $(\mathrm{B}, \mathrm{D}, \mathrm{E})$ and a disordered higher hydrate, with the hydrate formation pathway depending on the starting form and water activity. ${ }^{48}$ Structural analysis showed that OZPN I shares 1-D structural similarity with olanzapine dihydrate B (OZPN DB), dihydrate E and the higher hydrate and 2-D structural similarity to dihydrate D (OZPN DD). ${ }^{49}$ Whilst all 
neat and solvated solid forms of OZPN contain a centrosymmetric $(\mathrm{OZPN})_{2}$ dimer $\left(\mathrm{SC}_{0}\right)$ as a common structural building block (Figure 1c), the divalent cation has a non-dimeric packing arrangement in a number of OZPN salts. ${ }^{50,51}$ Crystal structure prediction (CSP) calculations have also indicated that OZPN structures without the dimeric motif are also thermodynamically feasible however have yet to be observed experimentally. ${ }^{47}$ OZPN and OZPN hydrates exhibit low aqueous solubility and there is interest in studying the mechanism of anhydrate to hydrate formation given the potential impact on performance and stability of OZPN shown in the study of Paisana et. al. ${ }^{48}$ In $93 \%$ relative humidity (RH), the moisture level drove the transformation of OZPN I to OZPN DD, while form II (containing form III as a phase impurity) was converted to OZPN DB. In a stirred aqueous environment, both forms were first transformed to kinetic OZPN DB (within 24 hours) and then to the more stable OZPN DD (after five days) suggesting either a solid-solid transformation or solution mediated transformation when exposed to controlled humidity or placed in direct contact with water respectively. Additionally, the structural similarities between the OZPN forms and corresponding dihydrates direct the different hydration outcomes under $93 \%$ RH.

In the case of OZPN, the impact of dissolution properties on drug product performance is critical.. Conversion to a more stable, less soluble hydrated form could compromise dissolution, however, transformations limited to the surface of the crystal would be difficult to detect by conventional techniques, e.g. XRPD. For this reason, crystals are typically suspended in aqueous solutions and stirring is used to drive transformations more or less to completion by continually refreshing the surface. It is generally assumed that transformations at extremely high humidity are the same but slower than those in stirred aqueous suspensions. Hence the present study investigates the heterogeneous nucleation of OZPN hydrates on anhydrous OZPN I crystals in 
aqueous suspension and on exposure to humidity, using AFM. Following on previous work ${ }^{48}$ this report investigates the effects of water activity, local mixing and structure on OZPN hydrate formation on the dominant face of OZPN I and provides evidence for two-step nucleation and surface templating. Extensive computational modelling including lattice matching, nanocrystal attachment and localised ledge interactions are used to explain the formation of the disordered phase and templating effect of the (100)OZPNI face for OZPN DD.

\section{MATERIALS AND METHODS}

Materials. All analytical grade solvents were purchased from Fisher Scientific, UK. NaCl (anhydrous, $\geq 99.5 \%$ ) was purchased from Sigma Aldrich UK, and OZPN from Molekula Ltd., UK, confirmed as form I by X-ray powder diffraction (XRPD), was used without further purification.

Crystallisation. OZPN I and OZPN dihydrates were prepared according to the methods described by Reutzel-Edens et. al. ${ }^{49}$ Single crystals of OZPN I were obtained by dissolving 200 $\mathrm{mg}$ of OZPN in $30 \mathrm{ml}$ of ethyl acetate. The solution was stirred and heated to ensure complete dissolution of OZPN. The solution was then filtered through a $0.45 \mu \mathrm{m}$ PTFE filter, transferred to $5 \mathrm{ml}$ glass vials, sealed and kept at room temperature (RT) for 3-5 days without stirring. The resulting crystals were filtered under vacuum and washed with a 1:1 ethyl acetate/ hexane mixture to remove any surface deposited material. Crystals were dried on a filter paper in a desiccator over a silica drying agent. OZPN DB and OZPN DD for Raman measurements were obtained by stirring $\sim 200 \mathrm{mg}$ of OZPN I in $3 \mathrm{ml}$ of water for $6 \mathrm{~h}$ and 8 days respectively. The presence of each dihydrate polymorph was then confirmed by XRPD.

OZPN I single crystal in water experiments. OZPN I single crystals (size between 1-1.5 $\mathrm{mm}$ ) were attached to the end of a glass capillary with epoxy glue, oriented so that $\{100\}$ OzPNI 
planes were exposed perpendicular to the capillary axis. The capillary was suspended in water so that when stirring was applied, the magnetic stirrer placed at the bottom of the vial was not in close contact with the crystal at the tip (Figure 3). Where specified as 'stirring conditions', the stirring rate was set as $100 \mathrm{rpm}$, otherwise no stirring was used. All experiments were performed at RT.

Raman Spectroscopy. Raman spectra were collected using a Thermo Scientific ${ }^{\mathrm{TM}}$ DXR Raman microscope with a $532 \mathrm{~nm}$ (diode-pumped, solid state) laser excitation source and CCD equipped with a high precision $\mathrm{X}, \mathrm{Y}, \mathrm{Z}$ motorized stage in the shift region of $50-3400 \mathrm{~cm}^{-1}$ over 10 scans using a resolution of $1 \mathrm{~cm}^{-1}$.

Optical Microscopy. Optical images were obtained using a Leica DM6000M optical microscope equipped with a motorized stage and Leica DFC495 camera. Images were analysed using LAS v.4.8 software (Leica).

X-ray Powder Diffraction (XRPD). XRPD patterns were obtained using a Bruker AXS D8Advance transmission diffractometer equipped with $\theta / \theta$ geometry, primary monochromated radiation $(\mathrm{Cu}, \lambda=1.54056 \AA)$. Data were collected in the $2 \theta$ range of $4-35^{\circ}$ with a $0.015^{\circ} 2 \theta$ step and $1 \mathrm{~s} /$ step speed. Reference powder patterns were produced using the Mercury 3.6 (CCDC) software from single crystal data (CSD ref. code OZPN I: UNOGIN01, OZPN DD: AQOMAU, OZPN DB: AQOMAU03).

Single Crystal Face Indexing. Crystals were indexed using a Bruker D8 Venture diffractometer equipped with a CCD detector and using graphite-monochromated $\mathrm{Cu} \mathrm{K} \alpha$ radiation ( $\lambda=1.54056 \AA)$ and an APEX-3 face indexing plug-in. 
Atomic Force Microscopy (AFM). AFM data were collected using a Dimension Icon AFM (Bruker) using PeakForce Tapping ${ }^{\circledR}$ mode at RT and a ScanAsyst Air probe (Bruker) with nominal spring constant $\mathrm{k}=0.4 \mathrm{~N} / \mathrm{m}$ and a nominal tip radius of $2 \mathrm{~nm}$.

AFM experiment in controlled relative humidity. OZPN I crystals were analysed at ambient (35\%) and higher (75\%) RH, with the latter achieved from ambient humidity using a saturated solution of $\mathrm{NaCl}$ and monitored throughout using a humidity sensor (Fisher Scientific). OZPN I crystals were mounted using double sided tape. Crystals were stored in a desiccator before analysis with no additional modification of crystal surfaces carried out before the measurements.

AFM experiments in water. OZPN I crystals were mounted with epoxy glue to a cover slip and placed in a crystallisation dish, which was submerged in $5 \mathrm{ml}$ of deionised water with no applied solution flow. Images were acquired using a ScanAsyst Fluid probe (Bruker) with nominal spring constant $\mathrm{k}=0.7 \mathrm{~N} / \mathrm{m}$ and a nominal tip radius of $2 \mathrm{~nm}$.

AFM Image Processing. All AFM data was analysed using NanoScope Analysis 1.5 software (Bruker). Height images were corrected by first order flattening.

Simulations. Morphology predictions. Crystal structures were geometrically optimized using the COMPASS force field in the Forcite module in Materials Studio 7.0 (Accelrys Software Inc.). The Quasi-Newton algorithm was used with convergence tolerance for energy of $2.0 \times 10^{-5}$ $\mathrm{kcal} / \mathrm{mol}$, a force of $0.001 \mathrm{kcal} / \mathrm{mol} / \AA$, and the displacement of $1.0 \times 10^{-5} \AA$. Growth morphology models of OZPN I, OZPN DD, OZPN DB were calculated using the Morphology Module (COMPASS force field with the Ewald summation method for electrostatic and van der Waals interactions with accuracy of $1.0 \times 10^{-5} \mathrm{kcal} / \mathrm{mol}$ with a buffer width $0.5 \AA$ ). The BFDH morphology models were generated using the Morphology Module with minimum interplanar distance $\mathrm{d} h \mathrm{hl}=0.8 \AA$. 
Epitaxial Matching Calculations. Epitaxial matching calculations were implemented using the GRACE (Geometric Real-space Analysis of Crystal Epitaxy) ${ }^{52}$ software package version 4.1. ${ }^{53}$ Epitaxial scores $(E)$ between (100) OzPNI and (001) OzPNDD or (100)OzPNDB were calculated by the summation of near coinciding lattice points between (100) OzPNI substrate and an overlayer of dihydrate as a function of the azimuthal angle between the two lattices ${ }^{36}$ for various search areas (ESI section 2 for details).

Modelling with atomistic models for the intermolecular forces. The intermolecular electrostatic interactions were modelled using distributed multipole models ${ }^{54,55}$ of the PBE0/631G(d, p) charge density of isolated OZPN and water molecules, to include the dominant anisotropy of the hydrogen bonding and $\pi-\pi$ electrostatic interactions. All other intermolecular interactions were modelled by an atom-atom exp-6 repulsion-dispersion potential using the empirically fitted FIT potential parameters. ${ }^{56}$ This type of model has been extensively used in crystal structure prediction studies ${ }^{57,58}$ including for olanzapine ${ }^{47}$ and organic hydrates. ${ }^{59,60}$ The rigid-molecule modelling for crystal structures used DMACRYS ${ }^{56}$. A variety of molecule $\cdots$ molecule, molecule $\cdots$ surface, molecule $\cdots$ ledge and nanocrystal $\cdots$ surface constructs were modelled using the same intermolecular potential within ORIENT, ${ }^{61}$ exploiting its capabilities for specific construction of an infinite perfect surface combined with other molecular units. ${ }^{62}$ Complete details are provided in the ESI.

\section{RESULTS}

\section{Characterisation of OZPN I crystals}

Form I OZPN is the most stable non-solvated crystal form and crystallises in space group P21/c. ${ }^{47,49}$ Single crystals can be obtained from several anhydrous solvents including ethyl acetate, isopropyl acetate, butyl acetate, isobutyl acetate, diethyl ether, diisopropyl ether, toluene, 
and fluorotoluene. ${ }^{47}$ Crystals prepared by slow evaporation of ethyl acetate solution are light yellow in color and show a rhombohedral morphology with large $\{100\}$ OZPNI faces and other smaller faces (Figure 1b; face-indexing of form I is shown in Figure S1a,b). Analysis of the crystal structure of OZPN I shows that hydrogen bonds link the centrosymmetric $\mathrm{SC}_{0}$ OZPN dimers ${ }^{47}$ into $2 \mathrm{D}$ layers parallel to (100)OZPNI (the orientation of the dimers on the (100)OZPNI face is shown in Figure 1c). With only the aromatic and methyl groups of OZPN decorating the (100)OZPNI surface, this face has a decidedly hydrophobic character. The dominant (100)OZPNI face observed from recrystallized samples is also the largest face present in the BFDH predicted morphology (Figure S2a), and is the face with the smallest attachment energy based on growth morphology calculation (Figure S2b, Table S1).

Crystals $(1-1.5 \mathrm{~mm}$ in size) grown from ethyl acetate solution were filtered, washed and dried (see Methods section). Optical microscopy shows well-formed facets (Figure 1b) and nanoscale surface characterization by AFM reveals a detailed ledge and terrace structure on the (100)OZPNI surfaces (Figure 2a). The ledges show a high kink density from the conditions used in their growth and preparation (Figure 2a), with a considerable number of them being [001] ozPNi ledges at an angle $\theta_{\mathrm{OZPNI}}=90^{\circ}$ comprising an (100) $)_{\mathrm{OZPNI}}$ terrace and an (020) OZPNI step (Figure 1d). The measured step height $\left(\mathrm{h}_{100}=10.12 \pm 0.81 \AA\right)$ correlates closely to the distance measured between (100) planes in an OZPN I crystal $\left(\mathrm{d}_{100}=10.17 \AA\right)$.
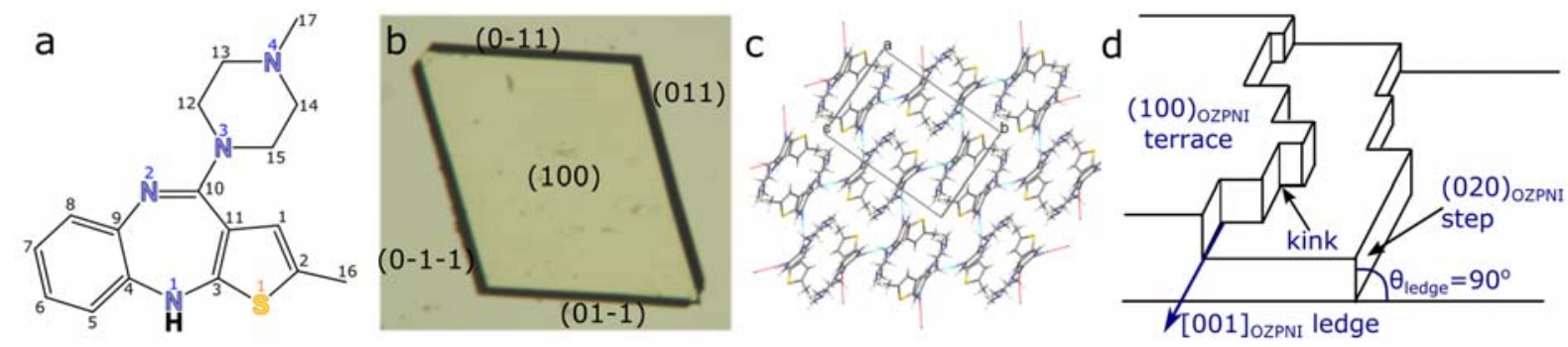
Figure 1 a) Molecular structure of OZPN. Numbering of the atoms according to reference ${ }^{47}$; b) single crystal of OZPN I obtained from slow evaporation of ethyl acetate solution, with face indices annotated (Figure S1); c) crystal structure of OZPN I (100)OZPNI face, showing SC 0 dimer pairs and d) schematic of (100) OzPNI crystal surface features observed using AFM (see Figure 2a).

\section{Nanoscale surface transformation in a humidity-controlled environment}

In situ AFM was used to investigate the mechanism of growth of OZPN DD on the surface of (100)OZPNI. Imaging was carried out under both ambient (35\% RH) and high humidity (75\% RH) conditions for $150 \mathrm{~min}$ and $6 \mathrm{~h}$ respectively. Prior to the measurements, crystals were maintained over a silica desiccant to prevent initiation of hydrate formation and surfaces were analysed without additional cleaning. Upon exposure of the crystal to $35 \% \mathrm{RH}$, multiple dome-shaped nanodroplets formed preferentially at high-energy kinks, ledges or defect sites on the (100)OZPNI terrace (Figure $2 \mathrm{a}-\mathrm{f}$ ). The initial diameter of the nanodroplets after 7 minutes (Figure $2 \mathrm{f}$ ) was $39.64 \pm 2.37 \mathrm{~nm}(\mathrm{n}=30$ droplets $)$. Under these conditions growth of nanodroplets appears to be associated with slow dissolution of surrounding OZPN layers characterized by pit site formation on the crystal face and recession of step edges (Figure 2d). It is assumed that the nanodroplets contain both OZPN and water molecules as a disordered dense phase. Over time, droplet coalescence is observed with those $>80 \mathrm{~nm}$ in diameter growing whereas smaller nanodroplets $(<60 \mathrm{~nm}$ in diameter) reduce in size and disappear over time (see Figure 2e). Within $150 \mathrm{~min}$, droplets grew to an average diameter of $139.84 \pm 31.42 \mathrm{~nm}(\mathrm{n}=30$, Figure $2 \mathrm{f})$. 

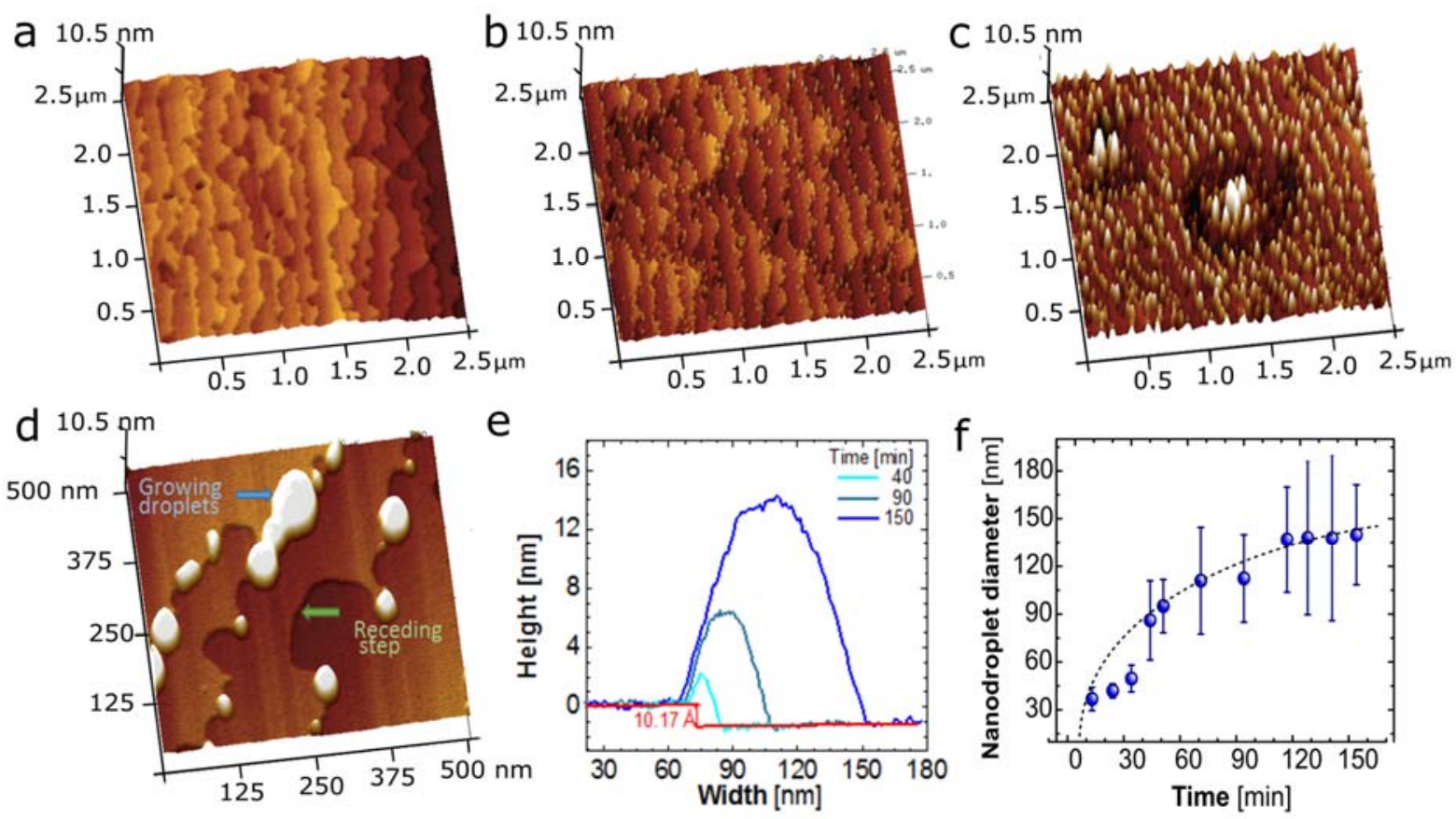

Figure 2 Growth of droplets on the surface of (100) OzPNI at $35 \% \mathrm{RH}$, AFM micrographs of (100)OZPNI showing surface changes (scan size $2.5 \mu \mathrm{m}$, z scale bar $10 \mathrm{~nm}$ ) at: a) $0 \mathrm{~min}$, b) 30 min, c) $113 \mathrm{~min}$, d) magnification of droplets after $113 \mathrm{~min}$ showing pit site formation and receding step edges during droplet growth, e) cross-sections of the droplets during various times, and f) growth of nanodroplets diameter over time. Each point is an average of $n=30$ droplets.

When OZPNI was subjected to $75 \%$ RH (Figure S5) similar processes were observed, with coalescence of smaller droplets to form larger nanodroplets $(102.77 \pm 39.90 \mathrm{~nm}, \mathrm{n}=30)$. When the crystal was held at $75 \%$ RH for 14 days and re-analyzed, the (100)OzPNI surface was entirely covered with droplets $(125.50 \pm 23.27 \mathrm{~nm}, \mathrm{n}=25)$ (see Supporting Information Figure S4e). Notably, no evidence of transformation of the nanodroplets to a new hydrated crystalline layer was observed. A previous report ${ }^{48}$ showed OZPN I gained very little moisture below $53 \% \mathrm{RH}(<$ $0.1 \% \mathrm{w} / \mathrm{w})$, increasing only slightly after 180 days at $75 \% \mathrm{RH}(0.27 \pm 0.07 \% \mathrm{w} / \mathrm{w})$, indicating that complete bulk transformation of OZPN I to dihydrate did not occur under these conditions 
even after prolonged exposure. Raman microspectroscopy of the OZPN I single crystal stored for 14 days in $75 \% \mathrm{RH}$ was unable to detect changes in the surface of OZPN I, most likely due to the very low thickness of the nanodroplet layer. However, based on the consistent droplet morphology there is no evidence to suggest that a transformation of the nanodroplets to a hydrated crystalline phase has initiated at $75 \% \mathrm{RH}$ within 2 weeks.

\section{Effect of stirring on OZPN dihydrate formation at (100) OZPNI solution interface}

In a stirred aqueous suspension of crystals, OZPN I transforms first to the kinetic OZPN DB within hours, followed by transformation to the most stable OZPN DD within days. ${ }^{48,49}$ To better understand these processes immobilized single crystals of OZPN I were suspended in water in vials with either gentle stirring $(100 \mathrm{rpm})$ or quiescent, unstirred conditions for $48 \mathrm{~h}$ (Figure $3 \mathrm{a})$. These different mixing environments for a suspended single crystal resulted in notable differences in the outcomes, and can be contrasted with conventional slurrying. In contrast with the OZPN humidity experiments, under all conditions, the formation of small plate-like crystallites was observed on the (100)OZPNI surface in water. However the orientation of the crystallites relative to the substrate crystal showed a dependence on stirring. When stirring was applied the microcrystallites did not exhibit significant preferential orientation relative to the substrate and were observed to be only loosely attached to the OZPN crystal surface. In contrast, microcrystallites grown under quiescent conditions were strongly bound to the (100)OzPNI crystal face and showed a significant and uniform degree of preferential orientation.

Raman microspectroscopy was used to determine the solid-state form of the observed crystallites formed under both conditions and the resultant spectra were compared to reference spectra for OZPN DB, OZPN DD, and OZPN I (Figure S3). The loosely bound crystallites obtained under stirred conditions were identified as OZPN DB, whilst the well-aligned, bound 
crystals produced under unstirred conditions were the thermodynamically stable dihydrate polymorph, OZPN DD. This was confirmed by single crystal X-ray analysis of crystallites carefully removed from the OZPN I samples surface. Face indexing of the dihydrate crystals (Figure S1c,d) allowed the relative orientation of OZPN DD and OZPN DB on the surface of (100) OZPNI to be determined. Morphological analysis of the OZPN DD and OZPN DB crystals identified that crystals grew with (001)OzPNDD and (100)OzPNDB parallel to (100)OzPNI respectively. The OZPN DB microcrystallites are randomly oriented on the surface of OZPN I, and so loosely adhered that they could be readily removed for analysis. This appears to be the result of crystallites forming close to the OZPN I surface rather in direct contact and remaining in close proximity rather than being cleared from the surface by shear and deposited elsewhere in the reactor. In contrast, OZPN DD crystallites were surface bound and oriented with [100] ozPNDD axis at $91^{\circ} \pm 2^{\circ}$ with respect to [010] OzPNI direction (see Supporting Information Figure S7).

The highly consistent orientation of OZPN DD microcrystals on OZPN I suggests a significant influence of the underlying OZPN I crystal structure on OZPN DD nucleation and growth under quiescent conditions. The strong dependence of the orientation between the substrate crystal and grown crystals is generally presumed to be controlled by an epitaxial mechanism, however GRACE analysis ${ }^{35,36,63}$ shows that there is no long range epitaxial match between the lattices of either dihydrate and the OZPN (100) face (ESI section 2). 

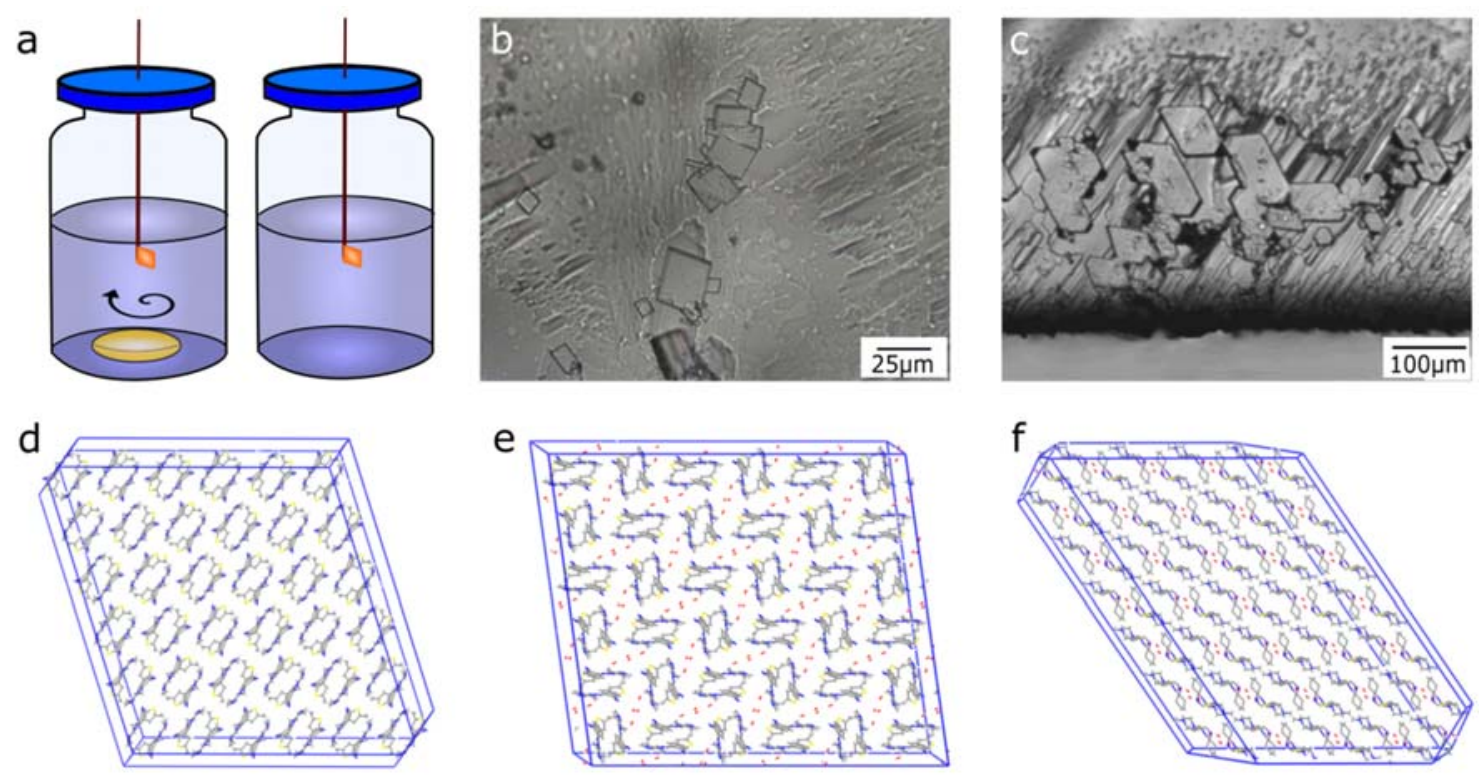

Figure 3 Effect of stirring on anhydrate to dihydrate transition. a) experimental set up: crystals attached to glass capillaries were placed in sealed vials and kept for $48 \mathrm{~h}$ in two different stirring conditions: gentle stirring (left; $100 \mathrm{rpm}$ ) and unstirred conditions (right). b) Optical image of the stirred (100) OZPNI surface of an OZPN I crystal with visible OZPN DB microcrystals after 6h, c) image showing OZPN DD microcrystals on OZPN I after $48 \mathrm{~h}$ in unstirred solution. Observed crystal morphologies of d) OZPN I with dimeric motif on (100) OzPNI and e) OZPN DB microcrystallites and molecular arrangement on (100)OZPNDB face, f) OZPN DD microcrystallites and molecular arrangement on (001)OZPNDD face. Face-indexing and relative orientation of microcrystals on OZPN I substrate are described in the ESI (Figures S1 and S7).

\section{AFM studies on (100)OzPNI in water.}

The OZPN I to dihydrate transformation in water is clearly influenced by the applied stirring/shearing conditions. To further investigate this, several OZPN I crystals were suspended in water and the (100)OzPNI face visualized by in situ AFM. Direct observation of the transforming surface using the scanning AFM probe can influence the surface. ${ }^{64}$ Therefore, in 
addition to continuous in situ monitoring over $24 \mathrm{~h}$, periodic monitoring of OZPN I samples stored under water was carried out to assess any influence of localised perturbations from the moving AFM probe.

Using longer scan intervals $(2 \mathrm{~h}, 24 \mathrm{~h}, 24.5 \mathrm{~h}, 25 \mathrm{~h}$ and $48 \mathrm{~h})$ the formation of the first nanodroplets occurred preferentially at the surface ledges together with local dissolution of OZPN (100) layers (Figure 4a). The fact these nanodroplets can be visualised in the aqueous environment, suggests they are significantly denser than liquid water and are OZPN-rich. The initial nanodroplet-like structures (lateral average diameter after 2 hours: $34 \pm 6 \mathrm{~nm}, \mathrm{n}=30$ ) are shown in (Figure 4a). There is also evidence of the dynamic nature of nanodroplets movement across the surface, with partial coalescence observed between neighbouring nanodroplets (two and many nanodroplets coalescing marked with dashed circle and yellow arrow respectively on Figure 4a, Figure S6). After 24 h, three scans with 30 min intervals were performed revealing a striking sequence of dynamic changes on the (100) OZPN I face. Coalescence of the nanodroplets progressively led to the formation of larger rounded rhombus-shaped features (Figure 4c, with height $127 \pm 34.20 \mathrm{~nm}$ and diameter $10.51 \pm 0.60 \mu \mathrm{m}$ ). In the periodic monitoring experiments after $24 \mathrm{~h}$, continued growth of the feature in all three dimensions was observed $(587.25 \pm 24.60 \mathrm{~nm}, 15.94 \pm 0.16 \mu \mathrm{m})$. Whilst the nanodroplet retains significant curvature (cross section Figure 4c) some partial ordering is apparent (e.g. emergence of more linear droplet edges) that may be a result of close association of the nanodroplet to the underlying crystal lattice of (100)OzPNI. Strikingly, after $48 \mathrm{~h}$ well-developed crystals are observed with the same morphology and orientation as described above for OZPN DD on the (100)OZPNI (Figure 4d, Figure S7d). 
After $2 \mathrm{~h}$ of continuous scanning, formation of the nanodroplets was also observed. The nanodroplets could be easily moved, dragged or even torn off by lateral shear forces of the probe and continued development of larger features was not observed, possibly due to disruption of the process by the AFM tip (Figure S5). Whilst nanodroplets are still observed to coalesce, the continuous movement of the probe apparently interferes with the association of the nanodroplets to the (100)OZPNI face. Notably no transformation to OZPN DD crystal was observed under continuous scanning. Thus the induction time for nucleation of crystals of OZPN DD from undisturbed nanodroplets, templated on the OZPN I surface, is significantly longer than the time to form the droplets. Disruption of the droplets during this period inhibits templated nucleation of OZPN by the underlying surface from the droplets.
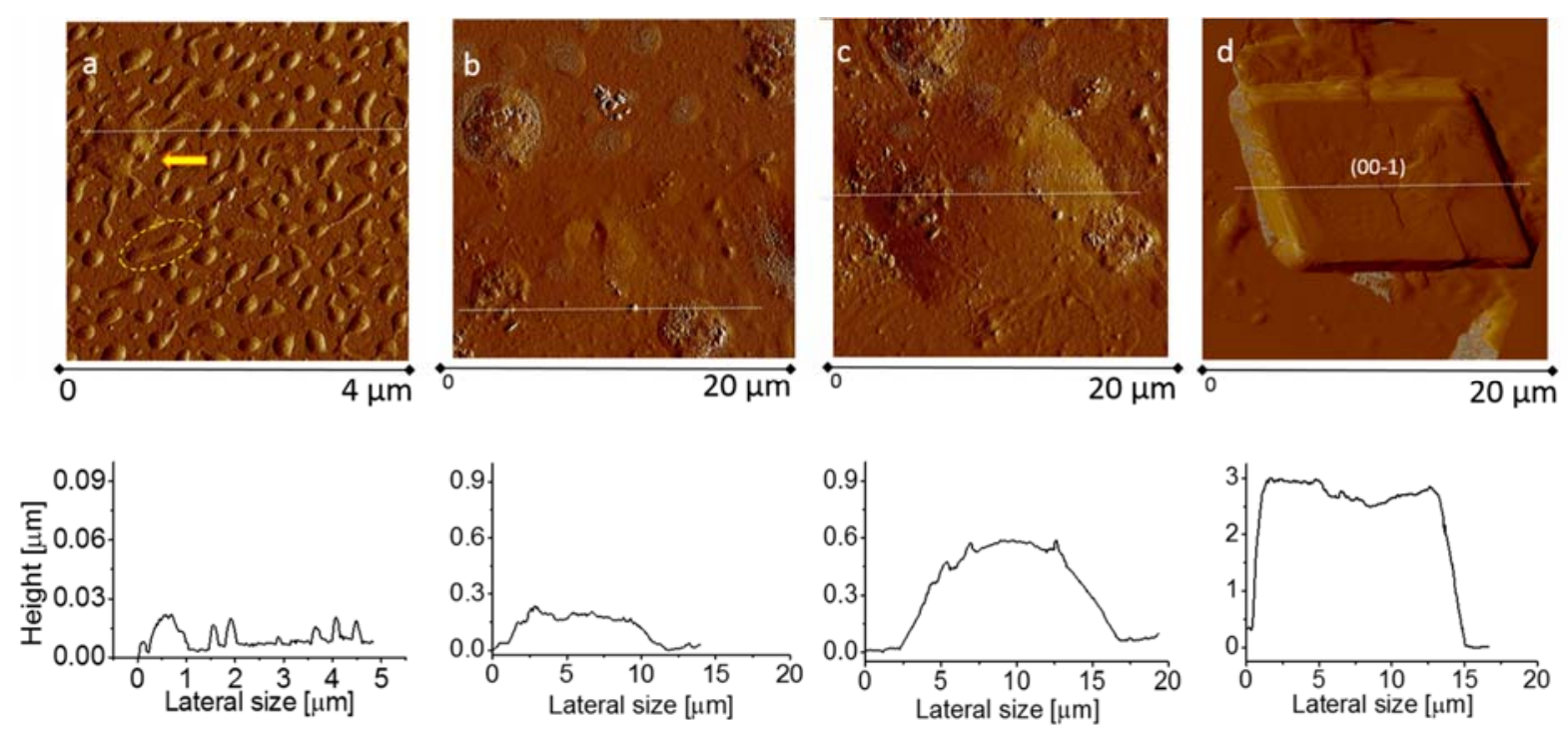

Figure 4 AFM micrographs with the corresponding cross section of height (area marked with dotted white line) of the surface of (100)OzPNI in water showing the evolution of size and ordered features after a) $2 \mathrm{~h}$ - visible droplets on the surface, droplet coalescence marked with yellow arrow and two droplets coalescing marked with dashed circle b) 24 h- coalescence of the 
droplets, c) 25 h- large coalesced droplet rearranging into rhombus shape, d) 48 h- fully developed OZPN DD crystal.

\section{DISCUSSION}

\section{Two-step nucleation process}

When OZPN I is exposed to humidity (93\% RH and above) or to an aqueous environment it undergoes transformation to the more stable OZPN dihydrate. ${ }^{47-49}$ The relatively slow rate of transformation of OZPN I to OZPN DD, with only partial surface transformation occurring after $48 \mathrm{~h}$ allows detailed study of the process using AFM. Building on previous report, ${ }^{48}$ the transformation of OZPN I in water is strongly dependent upon stirring, with quiescent conditions leading to direct growth of OZPN DD. Whilst the oriented growth of the resultant OZPN DD on (100) OZPNI is itself a striking finding, the details of the dynamic changes at the surface that precede the formation of these crystals is particularly unexpected. The formation, coalescence and growth of dense droplets preceding the nucleation of OZPN DD is not consistent with CNT and it is therefore proposed that OZPN DD nucleation on the surface of OZPN I is actually a two-step nucleation process (Figure 5). Formation of dense liquid domains in the range of several hundred nanometres leads to an unstable liquid phase that undergoes reorganization in a

later stage into an ordered crystalline structure via a two-step nucleation process, ${ }^{12-14,25,26,65}$ with the fundamental assumption of an increase in density prior to and separated from the development of crystallinity. ${ }^{13}$

AFM studies show that, when OZPN I single crystals are exposed to humidity $(35 \% \mathrm{RH})$, numerous nanodroplets form at high-energy kinks, ledges, or defects on (100)OZPNI terraces (Figure $5 \mathrm{~A}$ ). Condensation of water on the surface, presumably leads to localised dissolution of OZPN and nanodroplets increase in size by short-range molecular diffusion of OZPN molecules 
from adjacent crystal ledges, further water condensation and coalescence (Figure 5 B). However, the transformation from OZPN I to hydrated form under this condition (35\% RH) was not observed, consistent with reports that it can only occur to a significant extent at above $93 \%$ $\mathrm{RH}^{48}$

When suspended in aqueous solution, the aqueous OZPN nanodroplets can be visualised by AFM as a separate, solute rich dense liquid phase. Under quiescent conditions, the nanodroplets coalesce and transform to a mesoscopic feature with a rhombus shape (Figure 4c, and 5C). The shape of this feature is intriguing, evidently developing from the coalescence of smaller droplets and whilst no well-developed crystal facets are observed, the edges of the feature are approximately straight. The lateral profile of the observed mesodroplet (Figure $4 \mathrm{c}$ bottom) suggests that the nucleation process starts at the interface between (100) OZPNI and the droplet and appears strongly influenced by the crystal alignment of that face. The apparent evolution of ordering in the droplet suggests that nucleation occurs at the base of the drop in contact with the (100)OZPNI face and crystal growth progresses until the OZPN supersaturation has been consumed to form OZPN DD. Preferred orientation of OZPN DD microcrystallites on OZPN substrate suggests that (100)ozPNi plays a significant role in this process, templating the nucleation of OZPN DD from aggregated droplets (Figure 5D).

Based on the bifurcated formation of OZPN DB and DD microcrystals under stirred and unstirred conditions respectively (Figure 5), it can be concluded that the nanodroplets do not exhibit encoded structural information corresponding to either specific crystalline polymorph. ${ }^{20}$ Recent molecular simulations by Anwar et. al. ${ }^{66}$ showed that in situations where a crystal surface is present in a supersaturated solution, weakly bound spherical clusters of solute molecules immediately nucleate, when these clusters are in close contact with the surface. Nucleated 
clusters could be easily removed from the surface by agitation, leaving the surface able to seed further secondary nucleation. Taking into consideration the soft properties of nanodroplets observed in aqueous OZPN, and the relative ease by which they can be relocated (such as by a moving AFM probe), it is proposed that when exposed to shear through stirring, droplets are removed from the templating (100)OzPNI surface (Figure 5E). These solute rich droplets then coalesce and nucleate the kinetically-favored form OZPN DB in free solution (Figure 5F and G), with no direct influence of (100) OzPNI. Further work to confirm the presence of OZPN rich droplets in water solution, for example using light scattering techniques, is beyond the scope of this study. Nevertheless, similar behavior has been reported for the dependence of the magnitude of the contact force used during microattrition on the polymorphic outcome of glycine: $\alpha$-glycine was found more likely to nucleate at low forces due to removal of glycine rich clusters from the $\gamma$-glycine crystals, while using high forces led to secondary nucleation of the $\gamma$ form. ${ }^{67}$ Complete transformation of the OZPN I substrate crystal to OZPN DD was not observed, during these experiments due to slow transformation kinetics combined with reduced driving force from partial surface coverage.

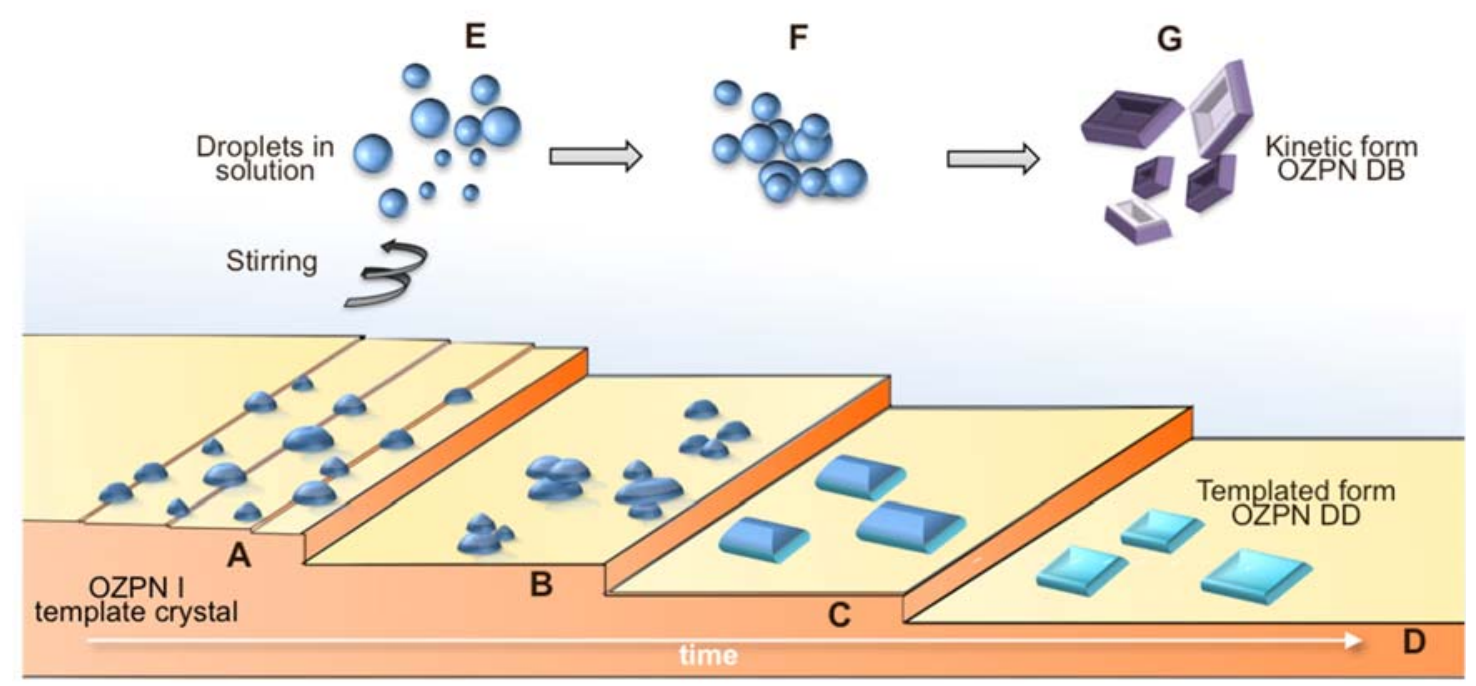


Figure 5 Schematic of the proposed nucleation process of OZPN DD on the surface of OZPN I crystal and OZPN DB in solution. Large steps (labelled A-D) represent major stages. In unstirred conditions nucleation follows $\mathrm{A} \rightarrow \mathrm{D}$ path resulting in formation of templated OZPN DD where A) shows formation of the droplets at ledge sites, B) coalescence of the droplets, C) formation of mesoscale droplets with emergence of crystalline features and D) fully developed OZPN DD crystal aligned on (100)OzPNI. Under stirred conditions, nucleation follows path $\mathrm{E} \rightarrow \mathrm{G}$ where E) static layer around the crystal is disturbed and droplets transfer into bulk solution, F) droplets coalesce in solution and G) the kinetic form (OZPN DB) crystals nucleate and grow in free solution.

\section{Role of OZPN I as a template}

Heterogeneous nucleation is practically widespread, albeit with containers, stirrers, impurities, particles/dust acting as the surface enhancing nucleation rates and possibly influencing resultant crystalline properties of materials. It is known that nucleation of a crystal is favourable on surfaces, as the interface promotes nucleation by lowering the nucleation free energy barrier. ${ }^{68}$ Indeed, well-chosen crystal surfaces can work as templates to crystallise novel polymorphs of organic molecules. ${ }^{37}$ To date, three major factors have been described as responsible for successful polymorph selection on crystalline templates: lattice matching (2-D epitaxy), ${ }^{34-37}$ molecular functionality of the substrate, ${ }^{38,69}$ and the substrate topology (ledge-directed epitaxy or LDE). ${ }^{32,33}$ However lattice matching and surface topology did not show sufficiently strong agreement between the substrate and the emergent form to suggest these were significant mechanisms for OZPN (ESI section 2).

\section{Modelling support for the two-step nucleation process}

Why molecules may not bind easily in crystallographic growth sites at ledges. 
To rationalise our explanation of a two-step nucleation mechanism for OZPN DD on (100) OZPNI face, a series of atomistic simulations was carried out using ORIENT, ${ }^{61}$ exploiting its unique capabilities for modelling specific constructions on an infinite perfect surface. ${ }^{62}$ Since all experimentally observed neat and solvated OZPN structures contain $\mathrm{SC}_{0}$ dimers (Figure 1) which are strongly bound by dispersion interactions, ${ }^{47}$ the $\mathrm{SC}_{0}$ dimer was assumed as the basic growth unit. As [001] ozPNI ledges were observed in AFM experiments to have dense droplets forming on it under humid conditions (Figure 2d), a [001] ozPNI ledge model was constructed (defined in ESI 3.2). A rigid $\mathrm{SC}_{0}$ dimer was docked onto the rigid ledge model by energy optimisation, starting from a grid of over 70 different initial positions above the surface with the dimer in the crystallographic orientation. During the optimization, the dimer moves and rotates under the influence of intermolecular forces and torques and binds to different sites on the ledge. The simulations of docking sites on the (100) OzPNI surface and [001] ozPNI ledge showed that there exists a multitude of sites at various positions on the ledge onto which a dimer could potentially dock in different orientations (Figure 6). A significant proportion of the optimisations showed the OZPN $\mathrm{SC}_{0}$ dimer binding preferably to the ledge site, compared to a direct docking onto the (100)OZPNI face. Whilst the crystallographic positioning of the dimer at the kink site (Figure 7a) is by far the most stable position, it can only be achieved when the dimer is approaching the ledge with the correct orientation and direction of approach, and was only found three times, despite the starting point having the correct orientation. This is due to the $\mathrm{SC}_{0}$ dimer being a highly anisotropic growth unit which needs to attach to the ledge by directional hydrogen-bonds, in this case, the N1-N2 sites on two adjacent $\mathrm{SC}_{0}$ dimers on the ledge, and the difficulty orienting itself correctly before docking onto the ledge. Thus the dimer was far more likely to become trapped in one of the other non-crystallographic positions, a few of which are shown in Figure 7 
b-e. Many of these positions are significantly more stable than a dimer docking onto the perfect surface which is very close to the crystallographic position, with a binding energy that is only slightly more stable than twice the attachment energy of $-37.6 \mathrm{~kJ} / \mathrm{mol}$. Hence, it appears that the ledges are more likely to attract $\mathrm{OZPN} \mathrm{SC}_{0}$ dimers from a range of orientations than the terraced surfaces, and consequently the dimeric growth units are expected to accumulate on the ledges. However, it is more than probable that they will have difficulty in binding onto the crystallographic position, as the existence of other alternative binding sites means they can be easily trapped on the ledges.

It is postulated that as a result of this complex binding process the accumulation and aggregation of $\mathrm{SC}_{0}$ dimers, retards surface integration. This is further hampered by the variety of weakly bound hydration sites for the molecule and dimer (ESI 3.4.2), the face (ESI 3.4.4) and ledge (ESI 3.4.5) and leads to the formation of the dense nanodroplets observed on the surface of (100) OZPNI.

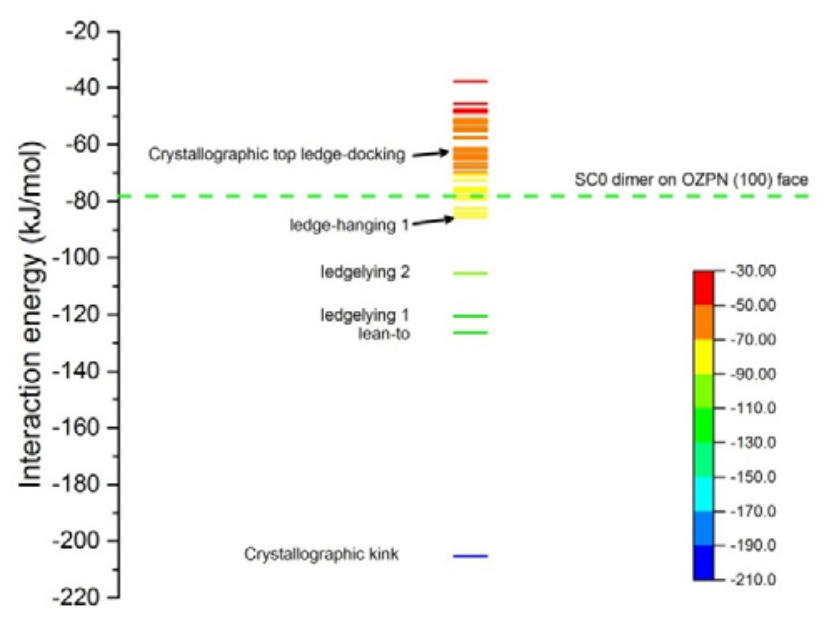

Figure 6 Interaction energies of $\mathrm{SC}_{0}$ dimer on OZPN I [001] ledge model on perfect (100)OZPNI surface. The reference energy of $\mathrm{SC}_{0}$ binding on (100) OZPNI face in the crystallographic position is shown as a dashed green line. 


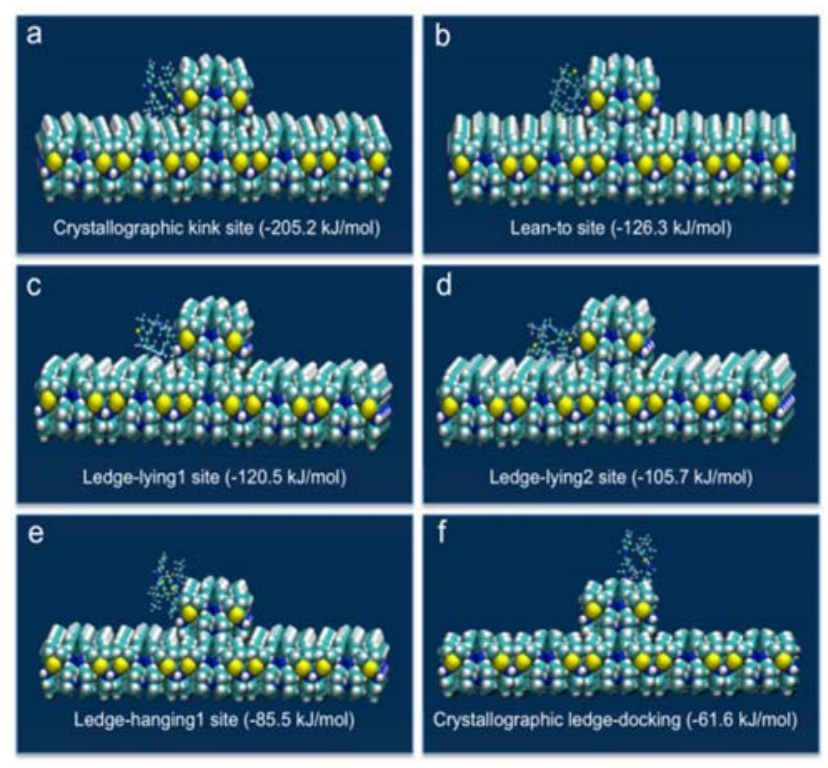

Figure $7 \mathrm{a}-\mathrm{f}$ ) A selection of representative binding sites for $\mathrm{SC}_{0}$ dimer on [001] ozPNI ledge model on a perfect (100) OZPNI surface.

This result is not dependent on the assumption that the $\mathrm{SC}_{0}$ dimer is the building block. The monomer, or any of the other possible dimers (ESI 3.4.1) would have similar or greater difficulty in accessing the crystallographic site. Some alternative dimers, and many hydrated dimers (given the range of hydration sites on the $\mathrm{SC}_{0}$ dimer (ESI 3.4.2) or any dimer-dimer complexes (ESI 3.4.3) would have to dissociate into $\mathrm{SC}_{0}$ dimer or monomers before adding to a crystallographic site, and may further block the growth. Hence any growth unit other than the $\mathrm{SC}_{0}$ dimer would further increase the extent of disorder on the surface ledge and further contribute to formation of a disordered solute-rich region containing both water and OZPN molecules.

The influence of OZPN I on the growth of OZPN DD and OZPN DB

To investigate why OZPN DD microcrystallites were observed with their (001) OzPNDD face firmly attached to the (100) OzPNI face, in contrast to the loosely attached (100) OZPNDB, nanocrystal models of both faces were constructed. These represent a small nucleating cluster that is large 
enough to establish the distinct hydrate crystal structures. The two nanocrystal constructs and the OZPN I surface are shown in Figure 8. This reveals that the (100)OZPNI face is hydrophobic and has a complex local topology, corrugated with large oval shaped peaks and pits. On the other hand different functional groups are exposed on the two dihydrate faces, presenting distinct chemical environments to the (100)OZPNI substrate face. The hydrophobic surface chemistry is also consistent with the observed resistance of OZPN I to wetting.
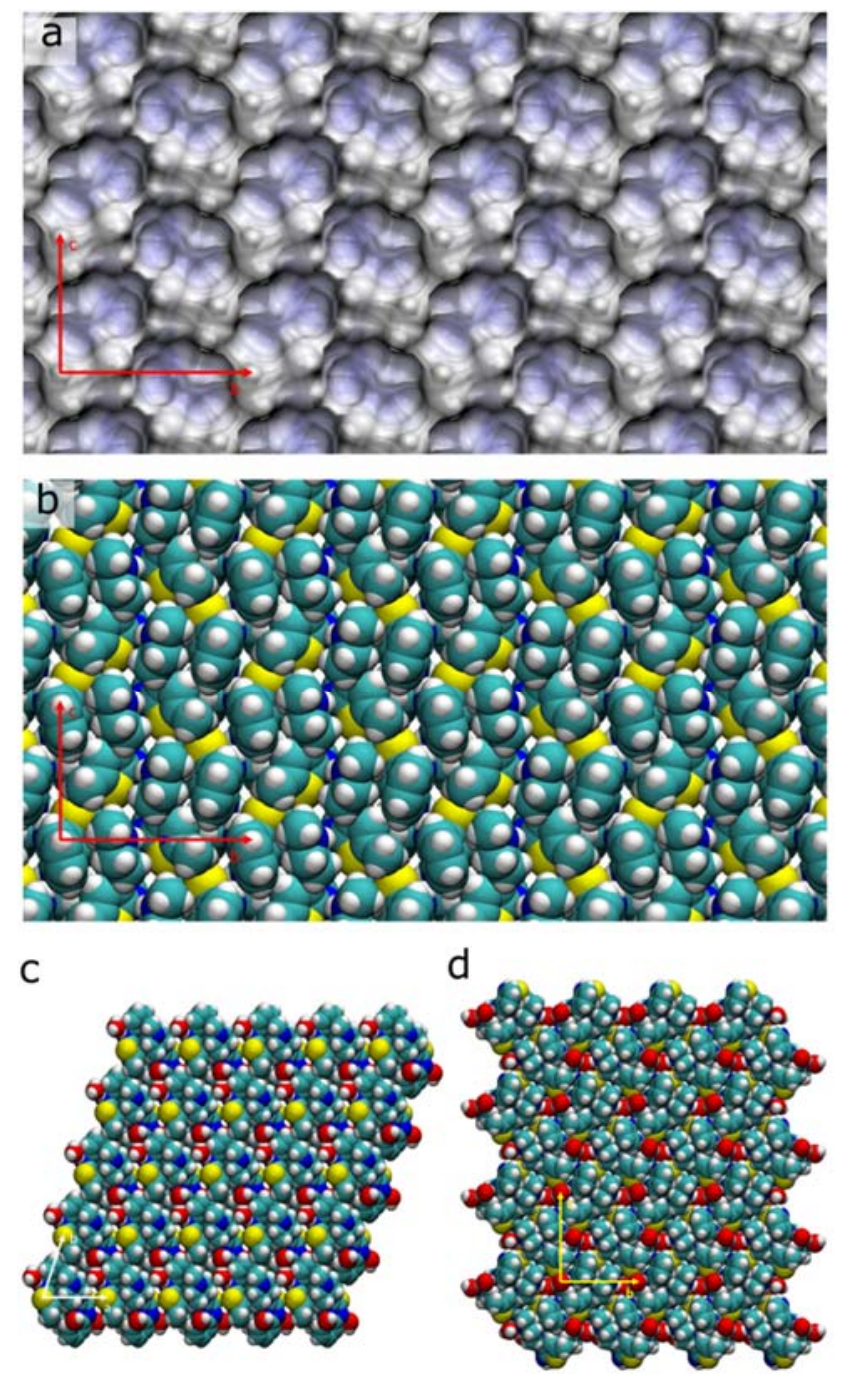

Figure 8 a) Top view of OZPN form I (100) face in a surface representation (white for surface bumps to blue pits, height difference about $3 \AA$ ) and b) vdW atomic representation (atoms are 
colour coded: carbon- green, hydrogen- white, sulphur- yellow, oxygen- red, nitrogen- blue); c) bottom view of OZPN DD nanocrystal (5x5) showing (001)ozPNDD face; d) bottom view of a OZPN DB nanocrystal (4x4) showing (100) OzPNDB face.

ORIENT was used to find the optimum binding energy of each nanocrystal with (100) OzPNI face (normalised to one $\mathrm{SC}_{0}$ dimer), as a function of the relative orientation and height of the two faces (Figure 9). The OZPN DD nanocrystal has a significantly stronger binding energy than OZPN DB for any orientation, with the average differing by $7 \mathrm{~kJ} / \mathrm{mol}$ per dimer. The weak binding between the OZPN DB nanocrystal and OZPN I is fairly independent of their relative orientation, consistent with the DB crystallites adhering to (100) OzPNI. The most favourable orientations of the OZPN DD nanocrystals are for $90-95^{\circ}$, consistent with the observed value of $91^{\circ} \pm 2^{\circ}$ (ESI Figure S7c and S17). The cause of this difference in the interactions between the two nanocrystals with (100) OzPNI is apparent from the molecular structure in the most favourable orientation (Figure 10).

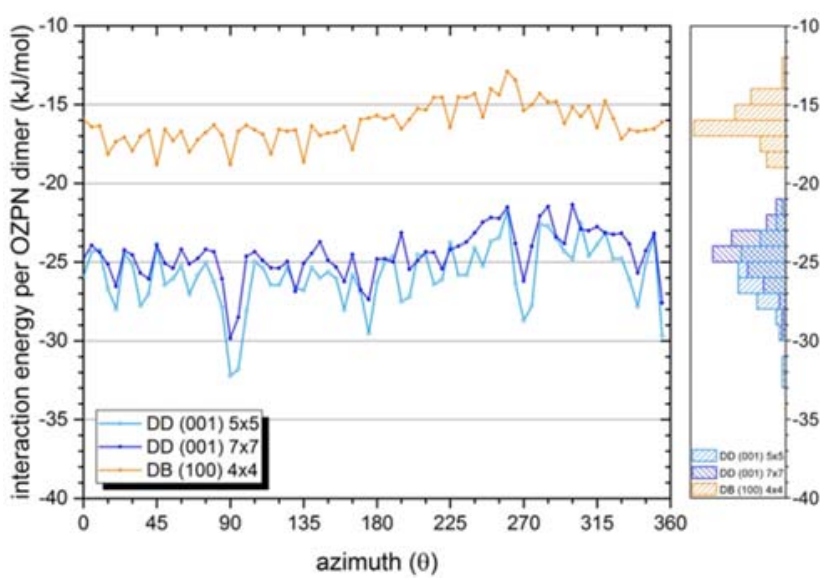

Figure 9 Interaction energies of (001)OZPNDD and (100)OZPNDB nanocrystals with OZPN I (100) face, normalized to be per OZPN dimer. Two different-sized nanocrystals are used for OZPN DD, which span the size of the OZPN DB nanocrystal, as a test of size dependence. Azimuthal angle $\theta=0^{\circ}$ corresponds to the angle between the [010] ozPNI and the [100] OzPNDD or [010] OZPNDB. 
In the most favourable orientation, the OZPN DD nanocrystal has the piperazine rings of OZPN DD in contact with the aromatic and alkyl $\mathrm{CH}_{n}$ groups of $(100)_{\text {OZPNI }}$ surface, though water molecules are also close (Figure 10a). The top view of the attached nanocrystal shows that along $[100]$ OzPNDD of the nanocrystal, there is a repeating pattern of close contacts between the bottom of the nanocrystals and the surface bumps. These are largely $\mathrm{CH}_{2} / \mathrm{CH}_{3}$ groups of piperazine rings and $\mathrm{CH}$ from aromatic rings on the substrate. This pattern of close contacts can be seen to shift gradually along [010] ozPNDD. However, the size of surface bumps means that nearly all OZPN DD unit cells maintain close contact with them. Hence there are close interactions between the molecules over a significant fraction of the surface, with quite a good degree of periodic repeats over this small area. There is a considerable area of van der Waals contact between the two surfaces, which increases the favourable dispersion interactions accounting for the larger binding energy. There are still significant void spaces between the two crystal structures. However, if the only favourable water binding site on (100)OzPNI (ESI 3.4.4) is occupied, then further water molecules could fill the void and hydrogen bond to the water molecules within the DD structure. Some relaxation of the nanocrystal could further enhance the binding, but such distortions will only be small. Hence, the nanocrystal calculations support the observation that (100)OzPNI templates the nucleation of OZPN DD, by favouring the formation of a sufficiently large nucleus with the OZPN DD structure to establish the growth of this phase. 

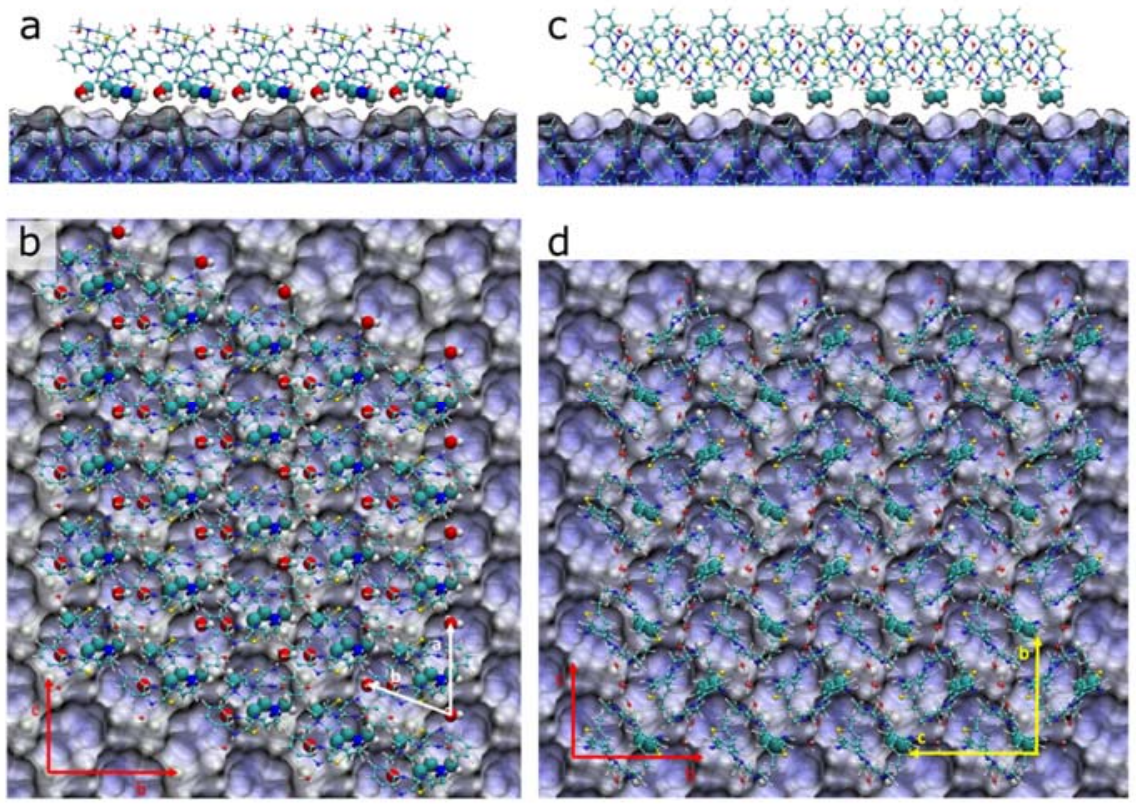

Figure 10 a) Side-view and top-view of the optimal attachment geometry at $\theta=90^{\circ}$ for (001)OZPNDD nanocrystal on (100)OzPNI face, with interaction energy of $32.20 \mathrm{~kJ} / \mathrm{mol}$ per OZPN dimer; (b) Side-view and top-view of the optimal attachment geometry at $\theta=90^{\circ}$ for (100) OzPNDB nanocrystal on (100) OzPNI face, with interaction energy of $18.79 \mathrm{~kJ} / \mathrm{mol}$ per OZPN dimer. $\theta=0^{\circ}$ corresponds to the angle between the [010] ozPNI and the [100] ozPNDD or [010] OZPNDB. Atoms in nanocrystals within a vertical distance of $3 \AA$ of the substrate were shown as CPK model. Surface representation colour scheme depicts surface height from blue low (pits) to white high (bumps). Unit cell vectors are shown in red for (100)OZPNI, white for (001)OZPNDD and yellow for (100)OZPNDB.

In contrast, the (100) OzPNDB face has less van der Waals contact with the (100) OzPNI surface, with only aromatic $\mathrm{CH}$ groups in contact with the hydrophobic OZPN surface, giving a smaller binding energy in all orientations. These aromatic ...aromatic contacts are still approximately periodically repeated, but there are significantly fewer close contacts between the other atoms in the two surfaces than in OZPN DD, providing less dispersion-stabilised binding (Figure 10c). 
The hydrophobic void space is much larger than for the OZPN DD nanocrystal, requiring a much larger cluster of water molecules to make any hydrogen bonding chain between (100) OzPNI N4 sites and the water molecules in the DB nanocrystal.

The extensive modelling work (detailed in ESI 3) supports the two-step nucleation process for OZPN. Unlike an isotropic spherical ("atomic") growth unit, OZPN molecules or dimers have difficulty in orienting easily into their crystallographic growth sites. There are multiple hydration sites on the ledge face (ESI 3.4.5) but only one on the (100)OzPNI surface, contributing to the formation of the dense OZPN/water droplets at ledge sites and impeding OZPN molecules from ordering into a crystallographic site, for either adding to the anhydrate or forming a dihydrate structure.

Once the prenucleation dense phase is present and nanodroplet coalescence has occurred, (100) OZPNI face is a better match, in terms of functional group interactions, with the (001) OzPNDD face structure than (100)OzPNDB. This is only apparent from explicitly modelling the intermolecular interactions, as the interaction between OZPN molecules are dominated by dispersion interactions. As either dihydrate crystal grows, the registry with the underlying surface will gradually decrease, but the nanocrystal models used are of a sufficient size to show the difference in the interactions and possibly to establish an effective nucleus for growth. The (100) OZPNI face has only one buried water binding site (ESI 3.4.4), being otherwise hydrophobic, so other waters are only bound by forming a water network. There is a stronger binding energy to encourage the formation of OZPN DD nucleus, displacing some of the water network on this surface, and for it to be more firmly attached than any crystallites of OZPN DB.

This hydration study is limited to a specific surface of a specific form of OZPN and in specific conditions which differ critically from a slurry conversion, in that there are no particle collisions 
that would refresh or produce different crystal surfaces. The kinetics are ideal for the application of AFM and are related to the low solubility of OZPN. However, the slow kinetics leading to surface hydrate formation at levels below that which are detected by conventional methods are highly relevant to long-term material storage behaviour. In this regard, this surface characterisation approach complements traditional methods of establishing phase stability over the shelf-life of the drug product. The epitaxial formation of hydrates is not widely reported, ${ }^{70}$ though this probably contributed to the common observation that API dissolution rates may decrease with time on storage. This example shows that more work on surface chemistry should unravel the complexity of the possible hydration and polymorph transformation pathways of pharmaceuticals such as OZPN.

\section{CONCLUSIONS}

The experimental and simulation approaches have shown a two-step nucleation mechanism in the formation of OZPN DD on the surface of the dominant face of OZPN I. Significant difference in the polymorphic outcome was observed with different stirring conditions owing to the reduced influence of the OZPNI surface on nucleation from droplets that have been removed from direct contact by shear. In quiescent conditions, only the presence of the thermodynamic form OZPN DD was observed on the surface of (100)OZPNI and AFM directly visualizes the formation of dense nanodroplets at ledge sites that are able to grow and coalesce until nucleation occurs. This two-step nucleation process results in a crystal closely bound to the OZPN I surface. The crystal form produced is templated by the (100) OzPNI surface which shows a structural similarity and energetic preference for OZPN DD over the metastable OZPN DB. Under stirred conditions, nanodroplets can be detached from the surface, resulting in the nucleation and formation of OZPN DB without any templating effect from (100) OZPNI surface. 
Examination of OZPN I surface properties, i.e. geometry, molecular functionality and crystal structure, showed that nucleation of OZPN DD occurs due to stronger intermolecular interactions between (100) OZPNI and (001) OzPNDD than with the largest face of OZPN DB. Even though a ledge-driven epitaxy mechanism was not observed, ledges play an important role in the nucleation process, by providing a site for the formation of dense droplets of OZPN and water molecules in prenucleation clusters, where the variety of stronger binding sites allows more OZPN $\mathrm{SC}_{0}$ dimers to accumulate, faster than onto the terraced surfaces.

Thus, OZPN hydration provides considerable insights into how pharmaceutical molecules, with their far from spherical shapes and highly anisotropic intermolecular interactions, do not conform to the models of crystal nucleation and growth for spherical isotropic growth units. Different crystalline forms present very different surface and ledge structures, allowing for different heteronucleation mechanisms and hence polymorph selectivity.

\section{ASSOCIATED CONTENT}

Supporting Information. Face indexing, morphology prediction, atomic force microscopy images Raman spectroscopy, GRACE calculations, angular-matching analysis, ORIENT modelling. This material is available free of charge via the Internet at http://pubs.acs.org.

\section{AUTHOR INFORMATION}

\section{Corresponding Author}

*E-mail: alastair.florence@strath.ac.uk

\section{ORCID}

Monika Warzecha: 0000-0001-6166-1089 
Sarah (Sally) L Price: 0000-0002-1230-7427

Dimitrios A. Lamprou: 0000-0002-8740-1661

Alastair J. Florence: 0000-0002-9706-8364

\section{Author Contributions}

The manuscript was written through contributions of all authors. All authors have given approval to the final version of the manuscript.

\section{Funding Sources}

The work was funded by EPSRC EP/K039229/1.

\section{ACKNOWLEDGMENT}

The authors thank the EPSRC Centre for Continuous Manufacturing and Crystallisation (CMAC) for an access to equipment, and Prof. Anthony Stone for the use of ORIENT.

\section{ABBREVIATIONS}

OZPN olanzapine, OZPN DB olanzapine dihydrate B, OZPN DD olanzapine dihydrate D,

\section{REFERENCES}

(1) Saleemi, A. N.; Rielly, C. D.; Nagy, Z. K. Cryst. Growth Des. 2012, 12, 1792-1807.

(2) Simone, E.; Zhang, W.; Nagy, Z. K. Cryst. Growth Des. 2015, 15, 2908-2919.

(3) Quon, J. L.; Chadwick, K.; Wood, G. P. F.; Sheu, I.; Brettmann, B. K.; Myerson, A. S.; Trout, B. L. Langmuir 2013, 29, 3292-3300.

(4) Sudha, C.; Srinivasan, K. CrystEngComm 2013, 15, 1914-1921.

(5) Davey, R. J.; Schroeder, S. L. M.; ter Horst, J. H. Angew. Chemie 2013, 52, 2166-2179. 
(6) Anwar, J.; Zahn, D. Angew. Chemie 2011, 50, 1996-2013.

(7) Gibbs, J. W. Trans. Connect. Acad. Arts Sci. 1876, 3, 108-248.

(8) Volmer, M.; Weber, A. Zeitschrift für Phys. Chemie 1925, 119, 277-301.

(9) Becker, R.; Döring, W. Ann. Phys. 1935, 24, 719-752.

(10) Frenkel, J. J. Chem. Phys. 1939, 7, 538-547.

(11) Kashchiev, D. Nucleation: Basic theory with applications; Butterworth-Heinemann, Oxford, 2000.

(12) Vekilov, P. G. Cryst. Growth Des. 2004, 4, 671-685.

(13) Vekilov, P. G. Nanoscale 2010, 2 (11), 2346-2357.

(14) Gliko, O.; Neumaier, N.; Pan, W.; Haase, I.; Fischer, M.; Bacher, A.; Weinkauf, S.; Vekilov, P. G. J. Am. Chem. Soc. 2005, 127, 3433-3438.

(15) Galkin, O.; Vekilov, P. G. Proc. Natl. Acad. Sci. U. S. A. 2000, 97, 6277-6281.

(16) Vekilov, P. G. Cryst. Growth Des. 2010, 10, 5007-5019.

(17) Malkin, A. J.; Kuznetsov, Y. G.; Land, T. A.; DeYoreo, J. J.; McPherson, A. Nat Struct Mol Biol 1995, 2, 956-959.

(18) Li, Y.; Lubchenko, V.; Vorontsova, M. A.; Filobelo, L.; Vekilov, P. G. J. Phys. Chem. B 2012, 116, 10657-10664.

(19) Li, Y.; Lubchenko, V.; Vekilov, P. G. Rev. Sci. Instrum. 2011, 82, 53106. 
(20) Gebauer, D.; Kellermeier, M.; Gale, J. D.; Bergström, L.; Cölfen, H. Chem. Soc. Rev. 2014, 43, 2348-2371.

(21) Gebauer, D.; Cölfen, H. Nano Today 2011, 6, 564-584.

(22) Nielsen, M. H.; Aloni, S.; Yoreo, J. J. De. Science. 2013, 218, 213-218.

(23) Sebastiani, F.; Wolf, S. L. P.; Born, B.; Luong, T. Q.; Cölfen, H.; Gebauer, D.; Havenith, M. Angew. Chemie 2017, 56, 490-495.

(24) Aber, J. E.; Arnold, S.; Garetz, B. A.; Myerson, A. S. Phys. Rev. Lett. 2005, 94, 1-4.

(25) Jawor-Baczynska, A.; Moore, B. D.; Lee, H. S.; McCormick, A. V.; Sefcik, J. Faraday Discuss. 2013, 167, 425-440.

(26) Jawor-Baczynska, A.; Sefcik, J.; Moore, B. D. Cryst. Growth Des. 2013, 13, 470-478.

(27) Jawor-Baczynska, A.; Moore, B. D.; Sefcik, J. Faraday Discuss. 2015, 179, 141-154.

(28) Peng, Y.; Wang, F.; Wang, Z.; Alsayed, A. M.; Zhang, Z.; Yodh, A. G.; Han, Y. Nat Mater 2015, 14, 101-108.

(29) Bera, M. K.; Antonio, M. R. J. Am. Chem. Soc. 2016, 138, 7282-7288.

(30) Ito, F.; Suzuki, Y.; Fujimori, J.; Sagawa, T.; Hara, M.; Seki, T.; Yasukuni, R.; Lamy de la Chapelle, M. Sci. Rep. 2016, 6, 1-6.

(31) Harano, K.; Homma, T.; Niimi, Y.; Koshino, M.; Suenaga, K.; Leibler, L.; Nakamura, E. Nat. Mater. 2012, 11, 877-881.

(32) Bonafede, S.; Ward, M. D. J. Am. Chem. Soc. 1995, 117, 7853-7861. 
(33) Tan, L.; Davis, R. M.; Myerson, A. S.; Trout, B. L. Cryst. Growth Des. 2015, 15, 21762186.

(34) Arlin, J.-B.; Price, L. S.; Price, S. L.; Florence, A. J. Chem. Commun. 2011, 47, 70747076.

(35) Lee, E. H.; Boerrigter, S. X. M.; Byrn, S. R. Cryst. Growth Des. 2010, 10, 518-527.

(36) Mitchell, C. a.; Yu, L.; Ward, M. D. J. Am. Chem. Soc. 2001, 123, 10830-10839.

(37) Srirambhatla, V. K.; Guo, R.; Price, S. L.; Florence, A. J. Chem. Commun. 2016, 52, $7384-7386$.

(38) Campione, M.; Sassella, A.; Moret, M.; Papagni, A.; Trabattoni, S.; Resel, R.; Lengyel, O.; Marcon, V.; Raos, G. J. Am. Chem. Soc. 2006, 128, 13378-13387.

(39) Lang, M.; Grzesiak, A. L.; Matzger, A. J. J. Am. Chem. Soc. 2002, 124, 14834-14835.

(40) Grzesiak, A. L.; Uribe, F. J.; Ockwig, N. W.; Yaghi, O. M.; Matzger, A. J. Angew. Chem. 2006, 45, 2553-2556.

(41) Musumeci, D.; Ward, M. D. CrystEngComm. 2011, 13, 1067.

(42) Chow, E. H. H.; Bučar, D.-K.; Jones, W. Chem. Commun. 2012, 48, 9210-9226.

(43) Pingali, K. C.; Shinbrot, T.; Cuitino, A.; Muzzio, F. J.; Garfunkel, E.; Lifshitz, Y.; Mann, A. B. Int. J. Pharm. 2012, 438, 184-190.

(44) Thakuria, R.; Eddleston, M. D.; Chow, E. H. H.; Lloyd, G. O.; Aldous, B. J.; Krzyzaniak, J. F.; Bond, A. D.; Jones, W. Angew. Chemie 2013, 52, 10541-10544. 
(45) Danesh, a; Connell, S. D.; Davies, M. C.; Roberts, C. J.; Tendler, S. J.; Williams, P. M.; Wilkins, M. J. Pharm. Res. 2001, 18, 299-303.

(46) Fulton, B.; Goa, K. L. Drugs 1997, 53, 281-298.

(47) Bhardwaj, R. M.; Price, L. S.; Price, S. L.; Reutzel-Edens, S. M.; Miller, G. J.; Oswald, I. D. H.; Johnston, B. F.; Florence, A. J. Cryst. Growth Des. 2013, 13, 1602-1617.

(48) Paisana, M. C.; Wahl, M. A.; Pinto, J. F. Int. J. Pharm. 2016, 509, 135-148.

(49) Reutzel-Edens, S. M.; Bush, J. K.; Magee, P. A.; Stephenson, G. A.; Byrn, S. R. Cryst. Growth Des. 2003, 3, 897-907.

(50) Thakuria, R.; Nangia, A. Cryst. Growth Des. 2013, 13, 3672-3680.

(51) Sarmah, K. K.; Sarma, A.; Roy, K.; Rao, D. R.; Thakuria, R. Cryst. Growth Des. 2015, $16,1047-1055$.

(52) Ward research group, University of New York.

(53) Stone, A. J. 2010, University of Cambridge.

(54) Stone, A. J. J. Chem. Theory Comput. 2005, 1, 1128-1132.

(55) Price, S. L.; Leslie, M.; Welch, G. W. A.; Habgood, M.; Price, L. S.; Karamertzanisc, P. G.; Dayd, G. M. Phys. Chem. Chem. Phys. 2010, 12, 8478-8490.

(56) Price, S. L.; Braun, D. E.; Reutzel-Edens, S. M. Chem. Commun. 2016, 52, 7065-7077.

(57) Price, S. L. Chem. Soc. Rev. 2014, 43, 2098-2111. 
(58) Braun, D. E.; Bhardwaj, R. M.; Florence, A. J.; Tocher, D. a; Price, S. L. Cryst. Growth Des. 2013, 13, 19-23.

(59) Braun, D. E.; Karamertzanis, P. G.; Price, S. L. Chem. Commun. 2011, 47, 5443-5445.

(60) Stone, A. J.; Dullweber, A.; Engkvist, O.; Fraschini, E.; Hodges, M. P.; Meredith, A. W.; Nutt, D. R.; Popelier, P. L. A.; Wales, D. J. 2015, University of Cambridge,.

(61) Engkvist, O.; Price, S. L.; Stone, A. J. Phys. Chem. Chem. Phys. 2000, 2, 3017-3027.

(62) Olmsted, B. K.; Ward, M. D. CrystEngComm . 2011, 13, 1070.

(63) Poloni, L. N.; Zhong, X.; Ward, M. D.; Mandal, T. Chem. Mater. 2017, 29, 331-345.

(64) Gliko, O.; Neumaier, N.; Fischer, M.; Haase, I.; Bacher, A.; Weinkauf, S.; Vekilov, P. G. J. Cryst. Growth 2005, 275, 1409-1416.

(65) Anwar, J.; Khan, S.; Lindfors, L. Angew. Chemie 2015, 54, 14681-14684.

(66) Cui, Y.; Myerson, A. S. Cryst. Growth Des. 2014, 14, 5152-5157.

(67) Debenedetti, P. G. Metastable Liquids: Concepts and Principals; Princeton University Press, 1996.

(68) Chadwick, K.; Chen, J.; Myerson, A. S.; Trout, B. L. Cryst. Growth Des. 2012, 12, 1159 1166.

(69) Rodríguez-Hornedo, N.; Lechuga-Ballesteros, D. Int. J. Pharm. 1992, 85, 149-162.

\section{BRIEFS}




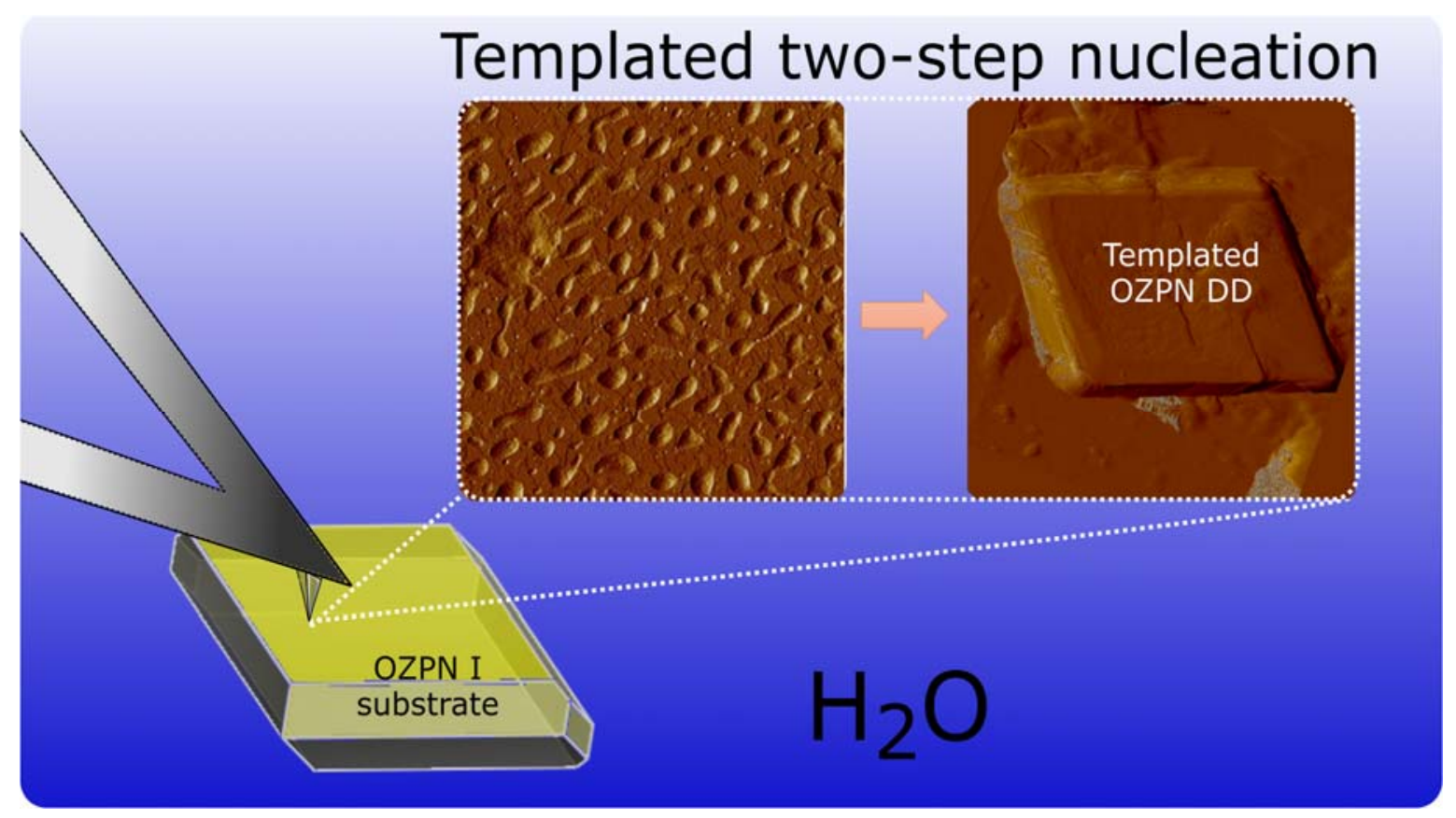

SYNOPSIS

The olanzapine anhydrous to dihydrate transformation in water follows a two-step nucleation mechanism and the selection of the specific dihydrate polymorphic form is dependent on the presence of olanzapine I as a template. 